\title{
Genetic counselling in retinoblastoma: importance of ocular fundus examination of first degree relatives and linkage analysis
}

\author{
Z Onadim, P G Hykin, J L Hungerford, J K Cowell
}

\begin{abstract}
We report an unusual family pedigree segregating the retinoblastoma predisposition gene. Expression of the phenotype in different individuals in this family ranges from asymptomatic gene carriers, regressed tumours, through unifocal to bilateral multifocal lesions. Because of the unusual pattern of inheritance in this family, initial genetic counselling at a local hospital did not take into account the possibility of incomplete penetrance of the gene, and complete ophthalmological examination of unaffected family members was not undertaken. We have used DNA probes from within the retinoblastoma predisposition gene for unequivocal identification of gene carriers. The subsequent demonstration of regressed tumours in founder members of the family confirmed the diagnosis of a dominantly inherited disease. The circumstances of the management of this family emphasises the need for specialist ophthalmic examination of first degree relatives and detailed genetic analysis of all such families with DNA probes.
\end{abstract}

Retinoblastoma ( $R B$ ) is the commonest primary malignant intraocular tumour in children and has both hereditary and sporadic forms. In familial cases the inheritance follows an autosomal dominant pattern, usually with high penetrance. Thus offspring of gene carriers have a $50 \%$ risk of inheriting the mutant gene. Although the retinoblastoma phenotype shows a dominant mode of inheritance, it is clear that at the cellular level additional mutations are required, since not all retinal cells produce tumours, and in approximately $10 \%$ of gene carriers tumours do not develop at all. This latter phenomenon is referred to as incomplete penetrance. Knudson' showed in a statistical analysis of $\mathrm{RB}$ that a single additional mutation was sufficient for tumorigenesis. This second mutation occurs sporadically in the homologous normal RB gene in retinal precursor cells. ${ }^{2}$ Hereditary cases are usually affected bilaterally, and, since the probability of the second mutation occurring is relatively high, the mean number of tumours in each eye averages four to five.

Retinoblastoma can also regress spontaneously, ${ }^{3}$ leaving characteristic retinal scars which often resemble successfully treated tumours. These may be compatible with normal visual acuity and remain undetected. The presence of multiple regressed tumours in a single individual or a single regressed tumour in an individual with relatives with $R B$ implies gene carrier status for those individuals and puts their children at approximately $50 \%$ risk of tumour development. It is essential therefore, to examine the retinae of parents of apparently sporadic cases.

The gene for $\mathrm{RB}$ predisposition - RB1 - was mapped to chromosome region 13q14 following observations that, in a small percentage of patients, predisposing constitutional chromosome deletions of this region were present. ${ }^{45}$ Genetic linkage analysis using the adjacent esterase-D gene confirmed that the hereditary non-deletion form of the disease was due to mutations on the same locus. ${ }^{6-8}$ The RBl gene was isolated by several groups independently ${ }^{9-11}$ and authenticated following the demonstration of mutations in this gene in tumour cells and predisposed persons. ${ }^{92-14}$ Individual unique DNA probes from within the genomic sequence of $\mathrm{RB} 1$, which recognised restriction fragment length polymorphisms (RFLPs), were isolated by Wiggs $e t a l^{15}$ which now form the basis of linkage analysis in RB families. ${ }^{15-17}$ So far no cases have been reported of genetic recombination between these DNA probes and the disease phenotype, and they have been used successfully in prenatal and perinatal prediction of carrier status. ${ }^{1718}$

Despite the now well characterised genetics of retinoblastoma and the availability of genetic probes for screening and counselling, advice to some familities is still sometimes incomplete. This is most often the case in families where the phenotype segregates with unusual characteristics. In this report we present the details of one such family as an example of the difficulty in making the correct prediction in the absence of genetic linkage data and ophthalmic examination of first degree relatives.

\section{Materials and methods}

DNA was prepared from white blood cells and lymphoblastoid cell lines by standard methods. ${ }^{19}$ All procedures for the analysis of DNA samples were as described previously. ${ }^{17}$

\section{Results}

The family pedigree is shown in Figure 1. The parents (II.6 and II.7) of the affected twins are first cousins and each has a sister affected by unilateral retinoblastoma. These observations are consistent with one or both of their parents (I.2 and I.3) being unaffected gene carriers. Family counselling was sought at a local hospital by the mother (II.7). In 1984, prior to their birth, a diagnosis of an autosomal recessive disorder was given at the local hospital by virtue 


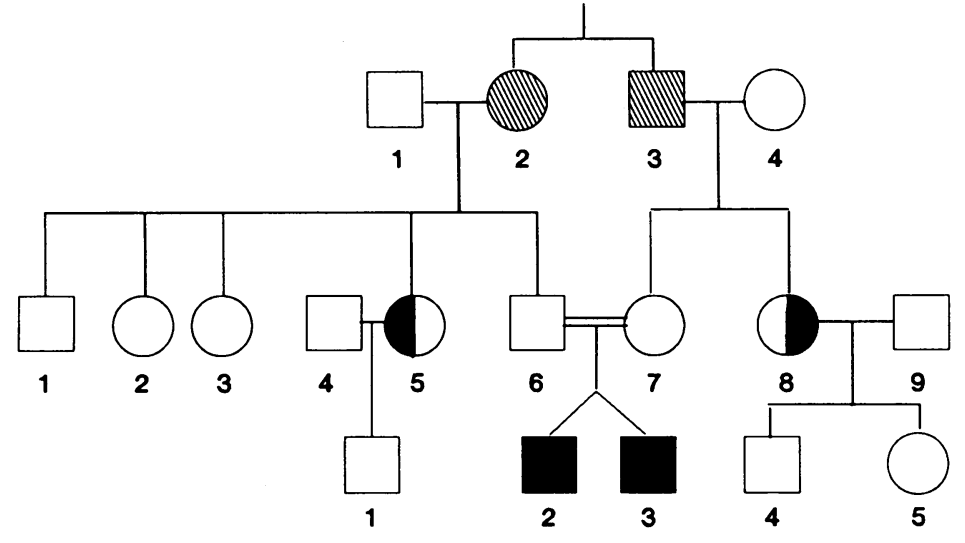

Figure 1 Family pedigree showing the segregation of the retinoblastoma phenotype. $\square=$ male. $\mathrm{O}=$ female. $\mathbf{Q}=$ affected bilaterally. $\mathrm{D}=$ affected unilaterally. $\Theta=$ regressed tumours.

of the fact that both parents had an affected sib, and a risk of having affected children of $1: 32$ was given. The retinae of the parents, I.2 and I.3, were not examined at this time.

In February 1987 non-identical twins were born, and in June of that year a diagnosis was made of bilateral retinoblastoma in both children at the age of 4 months following their referral to St Bartholomew's Hospital for treatment. Proband 1 had a juxtapapillary RB in the right eye and a posterior pole tumour in the left eye. Proband 2 had an RB nasal to the optic disc in the left eye and later developed a tumour temporal to the posterior pole in the right eye. No evidence of extraocular spread was discovered in either proband.

In July 1987 both grandparents attended the ophthalmology clinic at St Bartholomew's Hospital, where I.3 was found to have a large, grey translucent lesion at the posterior pole of the left eye (Fig 2). I.2 was found to have a small posterior pole lesion of the right eye which was translucent with pigment epithelial disturbance (Fig 3), and a small lesion nasal to the optic disc in the left eye. These lesions were typical of spontaneously regressed $\mathrm{RB}$. Close examination of the retinae of II. 6 and II. 7 showed no evidence of retinal scarring. Esterase-D studies showed all family members to be genotype 1-1. Chromosome analysis showed no deletions of the $13 \mathrm{q} 14$

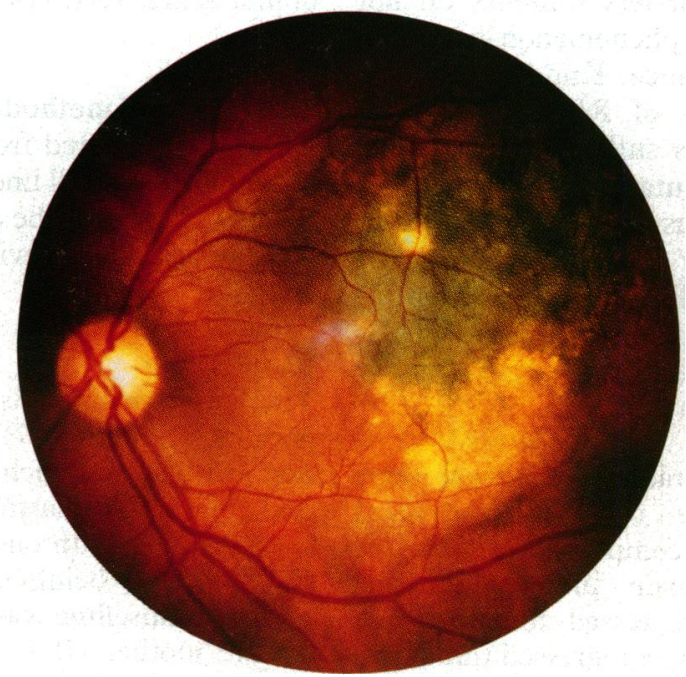

Figure 2 Large spontaneously regressed retinoblastoma at the posterior pole of the left eye of I.2. locus in any family member. At the time of the initial consultation DNA-based analysis was not generally available.

Since both parents are potentially unaffected gene carriers, there is a possibility that their children could be homozygous for the RB gene mutation. To investigate this possibility we used the intragenic RB DNA probe RS2.0, ${ }^{15}$ which recognises an 8 allele variable number tandem repeat (VNTR). We were able to follow the segregation of the chromosome 13 in this family, the details of which are given in figures 4 and 5 . Not all family members were available for analysis, and only the alleles for those from whom blood samples were obtained are shown.

Analysis of patients II.5 and II.8, the affected cousins, shows that the common alleles are 1.9 , which must have been derived from gene carriers I. 2 and I.3. Since both I. 2 and I. 3 showed evidence of retinal scarring it must be assumed that the 1.9 allele came from a common ancestor carrying the predisposing gene. Both parents II. 6 and II. 7 also carry the 1.9 allele. For II. 6 this allele was inherited from I. 2 but II. 7 received the 1.5 allele from her father and the 1.9 allele from the unrelated parent I.4. We would predict therefore that II.7 is not a gene carrier, thus excluding the possibility that their children could become homozygous for this mutation. The twins have inherited the 1.9 allele from their father, confirming the cosegregation of the RB phenotype with this allele. Analysis of the other members of the family shows that II. 1 is definitely not a gene carrier, since the 1.9 allele is missing, but, being homozygous for $1 \cdot 9$, II. 2 must be an asymptomatic gene carrier.

The affected patient II.5 is now homozygous for the 1.9 allele, which means that this probe will not be useful for future prenatal screening. In contrast II. 8 is heterozygous and could be offered prenatal screening in the future. The so far unaffected child in this family unit, III.4, is also homozygous for the $1.9 \mathrm{~Kb}$ allele, which places him at high risk for tumour development.

\section{Discussion}

In this unusual pedigree segregating the retino-

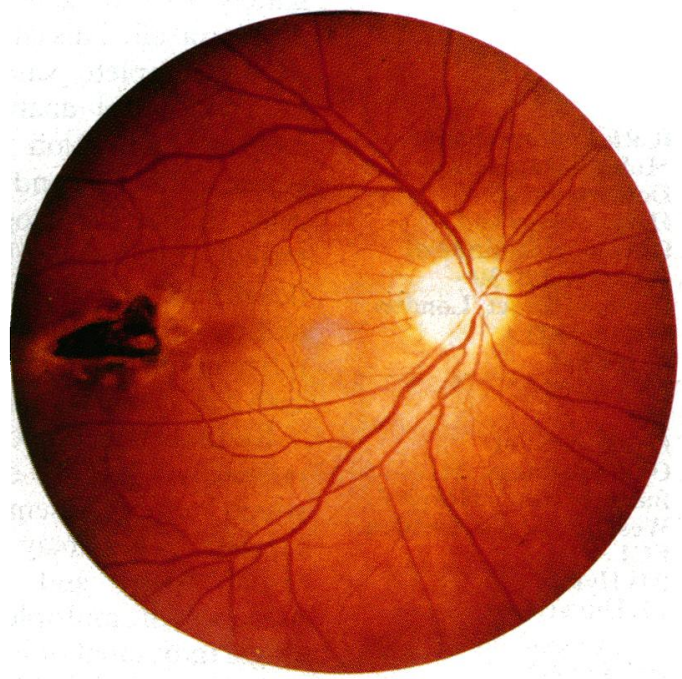

Figure 3 Small regressed retinoblastoma at the posterior pole of the right eye of $I .3$. 


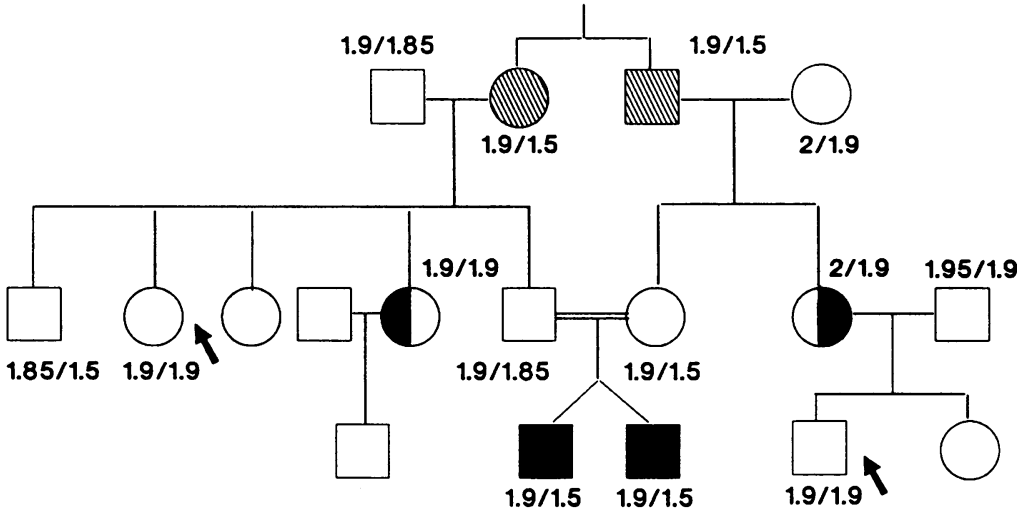

Figure 4 Segregation of the alleles identified by the RS2.0 DNA probe. The mutant retinoblastoma gene is segregating with the 1.9 allele. Asymptomatic gene carriers are indicated by the arrows. Symbols as in Figure 1. counselling. The segregation of the RB phenotype with the $1.9 \mathrm{~kb}$ allele in the core family allowed us to identify an unaffected gene carrier who has not yet begun her own family. Although this individual is homozygous for the $1.9 \mathrm{~kb}$ allele, and so would not qualify for prenatal screening with this probe, new screening procedures are being introduced with other polymorphisms which could be used. For individual II.8, who is heterozygous for the RS2.0 polymorphism, prenatal screening is available. The same service can be offered to the twins. We have also demonstrated that the parents of the twins are not both gene carriers, which excludes the possibility of their having children homozygous for the mutation. Since such homozygous. individuals have not been reported, it is not clear

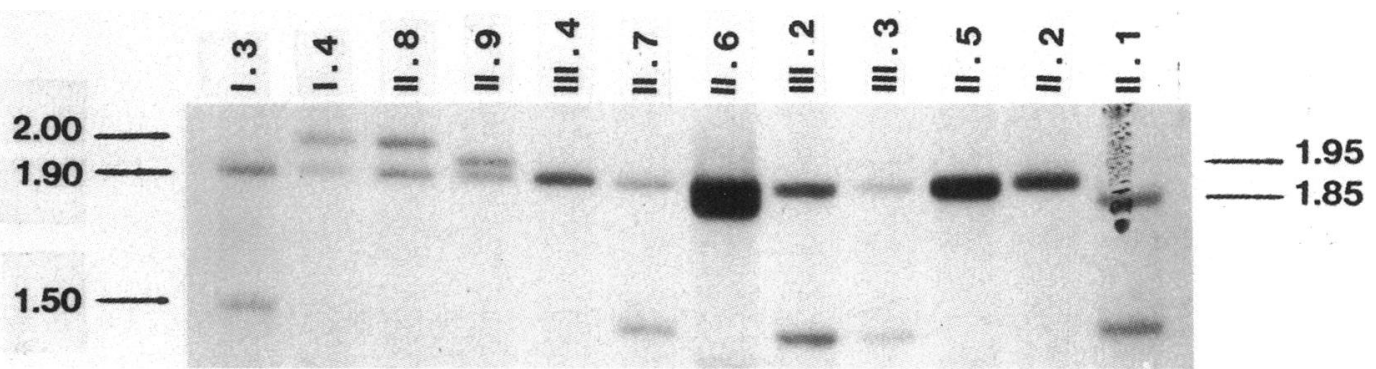

Figure 5 Southern blot analysis of key members of family $R B-29$ using the intragenic VNTR DNA probe RS2.0. In this family five different alleles $2.0 \mathrm{~kb}, 1.95 \mathrm{~kb}, 1.90 \mathrm{~kb}, 1.85 \mathrm{~kb}$, and $1.5 \mathrm{~kb}$ are segregating. The $R B$ predisposition gene segregates with the $1.9 \mathrm{~kb}$ allele.

blastoma predisposition gene there are both asymptomatic gene carriers and individuals with regressed tumours. In the second generation only unilaterally affected individuals are seen, which is unusual for predisposition gene carriers. ${ }^{1}$ We have observed several similar families ${ }^{17}$ in the past where the mutation appears to predispose to a 'milder' form of the disease, and there are other examples in the literature..$^{20}$ At the time of the first counselling sessions, before the patients were referred to St Bartholomew's Hospital, linkage/deletion analysis using the esterase-D polymorphism was in general use in the UK, ${ }^{821}$ though, being of genotype 1-1, this family would not have been informative. Recombinant DNA probes were not generally available until 1987. Examinations of apparently unaffected relatives, however, would have altered the advice given, and in our view this is an important first step in counselling such families. Because of the unusually low penetrance of the gene mutation in some families, this should be extended as far back in the pedigree as possible. Since the ophthalmoscopic appearance of regressed tumours may fall outside the experience of some ophthalmological practices, families or individuals should be referred to specialist centres for examination.

The identification of spontaneously regressed tumours in the grandparents in this case raised the risk to the children to $1: 2$ compared with the $1: 32$ risk offered at the time of first consultation. By establishing the phenotypes for the majority of the members of this family it was possible to perform linkage analysis with DNA probes. This analysis established several important points for what the expected phenotype might be, especially in 'mildly affected' pedigrees.

We thank Dr J Pritchard for his critical reading of the manuscript. Zerrin Onadim is supported by a grant from the David Allen Retinoblastoma Appeal.

1 Knudson AG. Mutation and cancer: statistical study of retinoblastoma. Proc Natl Acad Sci USA 1971; 68: 820-3.

2 Cavenee WK, Hansen MF, Nordenskjold M, et al. Genetic origin of mutations predisposing to retinoblastoma. Science 1985; 228 : 501-3

3 Gallie BL, Ellsworth RM, Abramson DH, Phillips RA. Retinoblastoma: spontaneous regression of retinoblastoma or benign manifestation of the mutation? Br 7 Cancer 1982 45: 513-21.

4 Lele KP, Penrose LS, Stallard HB. Chromosome deletion in a case of retinoblastoma. Ann Hum Genet 1963; 27: 171-4.

5 Vogel W. The genetics of retinoblastoma. Hum Genet 1979; 52 : $1-54$

6 Sparkes RS, Murphree AL, Lingua RW, et al. Gene for hereditary retinoblastoma assigned to human chromosome 13 by linkage to esterase-D. Science $1983 ; 217$ : 971-3.

7 Mukai S, Rapaport JM, Shields JA, Augsburger JJ, Dryja TP. Linkage of genes for human esterase-D and hereditary retinoblastoma. Am F Ophthalmol 1984; 97: 681-5.

8 Cowell JK, Jay M, Rutland P, Hungerford J. An assessment of the usefulness of electrophoretic variants of esterase $D$ in the antenatal diagnosis of retinoblastoma in the United Kingdom. Br F Cancer 1987; 55: 661-4.

9 Friend SH, Bernards R, Rogelj S, et al. A human DNA segment with properties of the gene that predisposes to retinoblastoma and osteosarcoma. Nature 1986; 323:643-6.

10 Fung YT, Murphree AL, T'Ang A, Qian J, Hinrichs SH, Benedict WF. Structural evidence for the authenticity of the human retinoblastoma gene. Science 1987 236: 1657-61.

11 Lee WH, Bookstein R, Hong F, Young L, Shew JY, Lee EP Human retinoblastoma susceptibility gene: cloning, identification and sequence. Science 1987; 235: 1394-9.

12 Dunn JM, Phillips RA, Becker A, Gallie BL. Identification of germline and somatic mutations affecting the retinoblastoma gene. Science 1988; 241: 1797-800.

13 Mitchell CD, Cowell JK. Predisposition to retinoblastoma due to a translocation within the $4 \cdot 7 \mathrm{R}$ locus. Oncogene $1989 ; 4$; 253-7.

14 Higgins MJ, Hansen MF, Cavenee WK, Lalande M. Molecular 
detection of chromosomal translocations that disrupt the putative retinoblastoma susceptibility locus. Mol Cell Biol 1989; 9: 1-5.

15 Wiggs J, Nordenskjeld M, Yandell D, et al. Prediction of the risk of hereditary retinoblastoma using DNA polymorphisms within the retinoblastoma gene. $N$ Engl F Med 1988; 318: 151-7.

16 Scheffer H, Te Meerman GJ, Kruize YCM, et al. Linkage analysis of families with hereditary retinoblastoma: nonpenetrance of mutation, revealed by combined use of markers within and flanking the RBl gene. Am $\mathcal{f}$ Hum Genet 1989; 45: 252-60.

17 Onadim Z, Mitchell CD, Rutland PC, et al. Application of blastoma gene carriers in the United Kingdom. Arch Dis Child 1990; 65: 651-6.

18 Mitchell CD, Nicolaides K, Kingston J, Hungerford J, Jay M, Cowell JK. Prenatal exclusion of hereditary retinoblastoma. Lancet 1988; i: 826.

19 Maniatis T, Fritsch EF, Sambrook J, eds. Molecular cloning: a laboratory manual. New York: Cold Spring Harbour Press, 1982: 1-406.

20 Connolly MJ, Payne RH, Johnson G, et al. Familial, EsD linked, retinoblastoma with reduced penetrance and variable expressivity. Hum Genet 1983; 65: 122-4.

21 Cowell JK, Rutland P, Jay M, Hungerford J. Deletions of the esterase-D locus from a survey of 200 retinoblastoma patients. Hum Genet 1986; 72: 164-7. 